\title{
ECMO during the COVID-19 pandemic: When is it justified?
}

\author{
Silver Heinsar ${ }^{1,2,3^{*}}$ (D) Giles J. Peek ${ }^{4}$ and John F. Fraser ${ }^{1,2,3}$
}

\begin{abstract}
Background
Abrams et al. recently introduced their view of extracorporeal membrane oxygenation (ECMO) utilisation during the COVID-19 pandemic as a burden-based approach, highlighting that surge conditions may result in decreased utilization of ECMO, as resources must be carefully managed to ensure an acceptable level of care in all patients [1]. Whilst case numbers may overwhelm some health care systems, thus making ECMO seem less attractive, we are offering an extended viewpoint where ECMO may be justified if systems are optimised to proceed without compromising the overall delivery of intensive care (Fig. 1).

The objective of this commentary is to provide general guidance, to expand on previously described suggestions by Abrams et al., on ECMO use during pandemic situations, especially while treating the critically ill patients with COVID-19.
\end{abstract}

\section{Conditions allowing for judicious use of ECMO Firstly, apply the best conventional intensive care before moving to ECMO.}

ECMO is a complex supportive treatment with inherent complications and significant economic implications. ECMO should only be considered when proven effective and relatively inexpensive measures such as proning, neuromuscular blockade and lung-protective ventilation have been tried without success. Omitting these steps without a valid reason prior to ECMO commencement

*Correspondence: s.heinsar@uq.edu.au

${ }^{1}$ Critical Care Research Group (CCRG), The Prince Charles Hospital, Chermside, Brisbane, QLD, Australia

Full list of author information is available at the end of the article is unjustified and a disservice to the global ECMO community.

Secondly, pick the right patients for the right treatment. The staggering contrast in outcomes of currently published ECMO reports amongst all COVID-19 patients tells a tale of different use of the same technology. The heterogeneity of COVID-19 patients with acute respiratory distress syndrome (ARDS) has been hypothesized by numerous authors, whilst no agreement on the existence and nature of possible sub-phenotypes exists [2, 3]. Furthermore, knowledge on COVID-19 atypical manifestations, such as predisposition to intrapulmonary thrombosis, right ventricular failure and the compounded immunologic insult by both COVID-19 infection and the extracorporeal circuit is yet to be fully explored. As the world is still waiting for comparative analyses of COVID19 ECMO patients, intelligent ECMO case selection using the available evidence-base is essential to facilitate each patients' recovery potential.

Considering the currently progressing global pandemic, we propose the use of advanced prediction models, which take into account regional differences, to complement expert opinions and various preliminary algorithms. Artificial intelligence (AI) and machine learning $(\mathrm{ML})$ are well suited to analysing large volumes of complex, heterogenous data in order to guide the lifecritical decisions intensivists are facing as the pandemic evolves [4].

As the global community is entering another wave of COVID-19, it's inevitable the demand for ECMO will exceed its supply. In case of multiple candidates with appropriate indications, ICUs will need to implement triage to select the most deserving candidates, with original author(s) and the source, provide a link to the Creative Commons licence, and indicate if changes were made. The images or other third party material in this article are included in the article's Creative Commons licence, unless indicated otherwise in a credit line to the material. If material is not included in the article's Creative Commons licence and your intended use is not permitted by statutory regulation or exceeds the permitted use, you will need to obtain permission directly from the copyright holder. To view a copy of this licence, visit http://creativecommons.org/licenses/by/4.0/. The Creative Commons Public Domain Dedication waiver (http://creativeco mmons.org/publicdomain/zero/1.0/) applies to the data made available in this article, unless otherwise stated in a credit line to the data. 


\section{Conditions for ECMO during COVID-19}
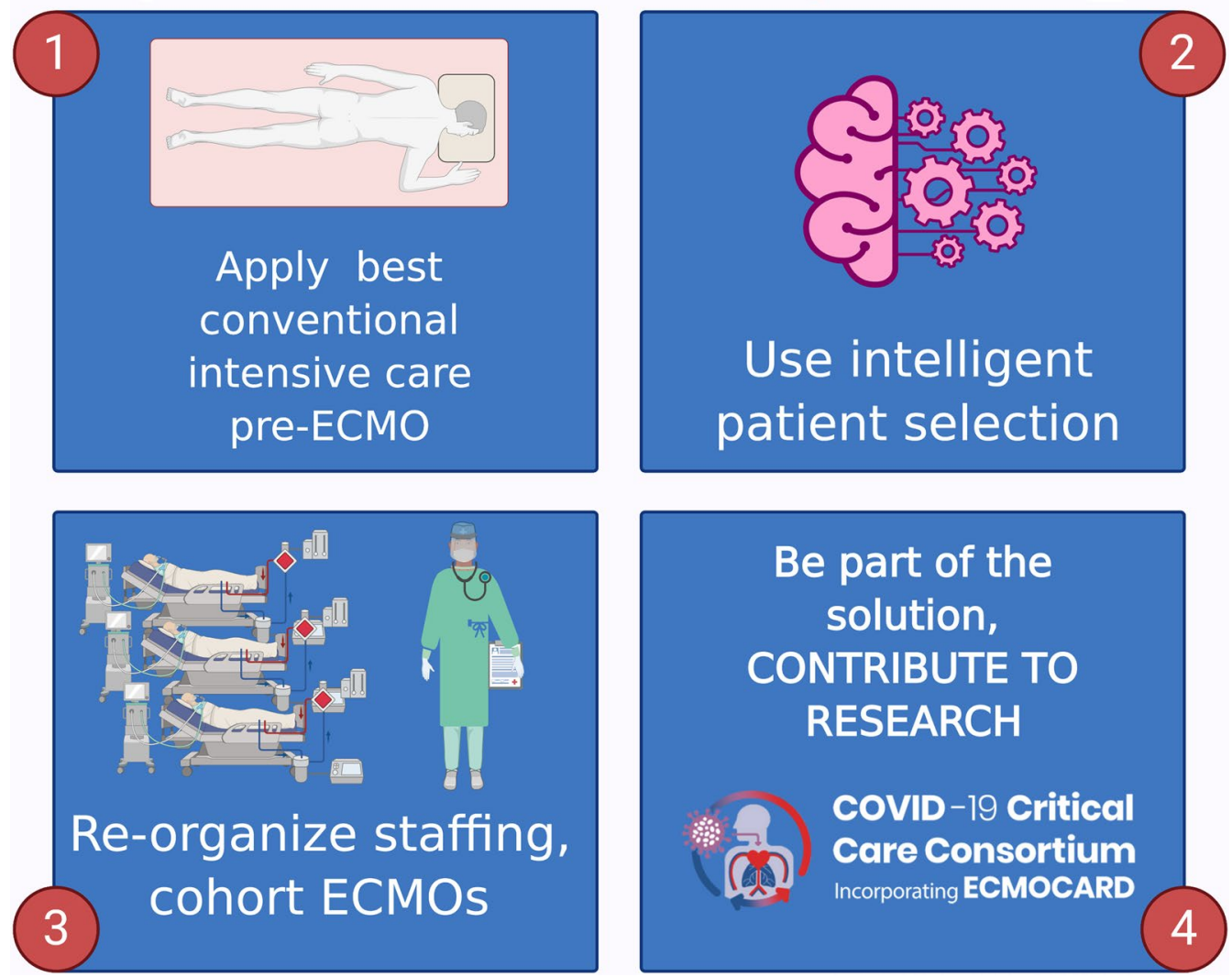

Fig. 1 Conditions for ECMO during pandemic situations. Everything starts with providing best conventional intensive care measures prior to ECMO. Careful filtering of patients, which can be facilitated with Al and machine learning support is critical to achieve good outcomes. Resource allocation can preserve the quality of care within the unit. And finally, experience needs to be translated to evidence and contributing to research is the way to make ECMO count

considerations including but not isolated to age, comorbidities and days ventilated.

\section{Thirdly, safely utilise fewer specialized ECMO staff for more} patients.

Resource allocation is the paramount in critical care during pandemic conditions. Cohorting ECMO patients and changing staffing ratios may facilitate satisfactory management of other ICU patients whilst not jeopardizing the general standard of care. The adoption of a allied health and nurse-driven program to ambulate patients on VV ECMO has been shown safe and may reduce other complications associated with immobility [5]. Furthermore, utilizing perfusionists as "ECMO specialists" can be done safely and could permit an expansive growth of ECMO in times of surge conditions [6]. Procedural management of ECMO must remain pragmatic and standardized to ensure staff burn out is prevented. Importantly, high-fidelity simulation programs are recommended as they reduce ECMO management time and improve teamwork [7].

\section{And finally, be part of the solution: contribute to research} Although well-conducted randomized controlled trials (RCTs) represent the best method of determining the efficacy of medical interventions, the eligibility criteria proposed by RCTs can make them unrepresentative of a wide population of patients. In addition, they are costly and time-consuming, particularly for medical devices such as ECMO. Factors such as low enrolment rate and crossovers also contribute to the impracticality of conducting large and timely RCTs of ECMO in critically ill patients, limiting the feasibility of applying this gold standard $[8,9]$. Furthermore, a recently published meta-analysis combining 429 patients with ARDS from two large RCTs (CESAR and EOLIA) found significantly lower mortality in those treated with ECMO compared to conventional management, highlighting that additional efficacy trials in ECMO for ARDS are unnecessary 
[10]. Due to inappropriateness of a new RCT comparing different ECMO technologies, we recommend the use of modern causal inference methods, such as propensity matched pair analysis, to scale down the effect of confounding [11, 12]. Registries and consortiums collecting observational data on COVID-19 related ECMO are paramount to synthesize supportive evidence from geographically fragmented data, as ECMO remains a last resort measure, carefully selected for the sickest of the sick. Numerous large-scale registries collecting ECMO data in COVID-19 patients exist [13-15]. As clinical researchers, we urge all centres with capacity to perform ECMO support during this pandemic to find the most suitable and feasible way to collect and report their clinical data for maximal utilisation of clinically generated experience.

\section{Conclusion}

In conclusion, whilst health care facilities must balance their intensive care resources with the fluctuations of patient volume as described by Abrams and colleagues, it's imperative to ensure they've adhered to the highest standard of care prior to ECMO, used innovative and evidence-based solutions to decide who goes on ECMO, allocate specialized staff for those on ECMO to preserve the standard of care within the unit, and ensure their work gets translated to science and innovation by joining promising research endeavours in this field.

\section{Acknowledgements}

Figure 1 was created with BioRender.com.

\section{Authors' contributions}

SH wrote the first draft of the manuscript. GJP and JFF reviewed and edited the manuscript. All authors read and approved the final manuscript.

\section{Funding}

None.

\section{Availability of data and materials}

Not applicable.

\section{Ethics approval and consent to participate}

Not applicable.

\section{Consent for publication}

Not applicable.

\section{Competing interests}

The authors declare that they have no competing interests.

\section{Author details}

${ }^{1}$ Critical Care Research Group (CCRG), The Prince Charles Hospital, Chermside, Brisbane, QLD, Australia. ${ }^{2}$ Faculty of Medicine, University of Queensland,
Brisbane, QLD, Australia. ${ }^{3}$ St Andrews War Memorial Hospital, Brisbane, QLD, Australia. ${ }^{4}$ Shand's Congenital Heart Center, University of Florida, Gainesville, $\mathrm{FL}$, USA.

Received: 28 October 2020 Accepted: 12 November 2020

Published online: 19 November 2020

\section{References}

1. Abrams D, Lorusso R, Vincent J-L, Brodie D. ECMO during the COVID-19 pandemic: when is it unjustified? Crit Care. 2020;24(1):507.

2. Gattinoni L, Chiumello D, Caironi P, Busana M, Romitti F, Brazzi L, et al. COVID-19 pneumonia: different respiratory treatments for different phenotypes? Intensive Care Med. 2020;46(6):1099-102.

3. Sinha P, Calfee CS, Cherian S, Brealey D, Cutler S, King C, et al. Prevalence of phenotypes of acute respiratory distress syndrome in critically ill patients with COVID-19: a prospective observational study. Lancet Respir Med. 2020;10:10. https://doi.org/10.1016/S2213-2600(20)30366-0.

4. Lovejoy CA, Buch V, Maruthappu M. Artificial intelligence in the intensive care unit. Crit Care. 2019;23(1):7.

5. Boling B, Dennis DR, Tribble TA, Rajagopalan N, Hoopes CW. Safety of nurse-led ambulation for patients on venovenous extracorporeal membrane oxygenation. Prog Transplant. 2016;26(2):112-6.

6. Mongero LB, Beck JR, Charette KA. Managing the extracorporeal membrane oxygenation (ECMO) circuit integrity and safety utilizing the perfusionist as the "ECMO Specialist." Perfusion. 2013;28(6):552-4.

7. Di Nardo M, David P, Stoppa F, Lorusso R, Raponi M, Amodeo A, et al. The introduction of a high-fidelity simulation program for training pediatric critical care personnel reduces the times to manage extracorporeal membrane oxygenation emergencies and improves teamwork. J Thorac Dis. 2018;10(6):3409-17.

8. Combes A, Hajage D, Capellier G, Demoule A, Lavoué S, Guervilly C, et al. Extracorporeal membrane oxygenation for severe acute respiratory distress syndrome. N Engl J Med. 2018;378(21):1965-75.

9. Gattinoni L, Vasques F, Quintel M. Use of ECMO in ARDS: does the EOLIA trial really help? Crit Care. 2018;22(1):171.

10. Combes A, Peek GJ, Hajage D, Hardy P, Abrams D, Schmidt M, et al. ECMO for severe ARDS: systematic review and individual patient data metaanalysis. Intensive Care Med. 2020;6:1-10.

11. Hernán MA, Robins JM. Using big data to emulate a target trial when a randomized trial is not available. Am J Epidemiol. 2016;183(8):758-64.

12. Admon AJ, Donnelly JP, Casey JD, Janz DR, Russell DW, Joffe AM, et al. Emulating a novel clinical trial using existing observational data. Predicting results of the PreVent study. Ann Am Thorac Soc. 2019;16(8):998-1007.

13. Barbaro RP, MacLaren G, Boonstra PS, Iwashyna TJ, Slutsky AS, Fan E, et al. Extracorporeal membrane oxygenation support in COVID-19: an international cohort study of the Extracorporeal Life Support Organization registry. Lancet.

14. European/euro-ELSO survey on adult and neonatal/pediatric COVID-19 patients in ECMO. https://ClinicalTrials.gov/show/NCT04366921.

15. Li Bassi G, Suen J, Barnett AG, Corley A, Millar JE, Fanning JP, et al. The COVID-19 Critical Care Consortium observational study: design and rationale of a prospective, international, multicenter, observational study. medRxiv. 2020:2020.05.29.20115253.

\section{Publisher's Note}

Springer Nature remains neutral with regard to jurisdictional claims in published maps and institutional affiliations. 